\title{
PENINGKATAN KESEHATAN PADA REMAJA TENTANG REPRODUKSI SEHAT MENUJU GENERASI HEBAT
}

\author{
Maimaznah $^{1)}$, Iin Indrawati ${ }^{2)}$ \\ 1,2) Program Studi D-III Keperawatan, STIKBA Jambi \\ email: mai732373@gmail.com
}

\begin{abstract}
Teenagers generally face problems about sexuality and reproductive health due to limited information and advocacy, no access to friendly services to adolescents, limited institutions in the government that handle adolescents in particular, there is no law that accommodates adolescent rights, and there is no health curriculum reproduction in adolescents. The results of the survey in Karang Kota Village found that there were still many adolescents who did not know about reproductive health, there were incidents of teenagers becoming pregnant outside of marriage and getting married at a young age $(<20$ years). The target and outcome of this community service activity are adolescents who obtain appropriate information about reproductive health and understand and can carry out in their daily lives to improve adolescent health, especially reproductive health. The stages carried out in this activity include: 1). conduct a survey to the location (Kota Karang Village, Kumpeh Ulu District), 2). looking for information about adolescent health in Kota Karang Village, Kec. Kumpeh Ulu, 3). do health promotion in Kota Karang Village, Kec. Kumpeh Ulu, and 4). conduct an evaluation of the promotion carried out. Teenagers get the right information about reproductive health and understand and can carry out in daily life to improve adolescent health, especially reproductive health.
\end{abstract}

Keywords: health improvement; teenagers; healthy reproduction

\begin{abstract}
ABSTRAK
Remaja umumnya menghadapi permasalahan tentang seksualitas dan kesehatan reproduksi yang disebabkan terbatasnya informasi dan advokasi, tidak ada akses pelayanan ramah terhadap remaja, masih terbatasnya institusi di pemerintah yang menangani remaja secara khusus, belum ada UU yang mengakomodir hak-hak remaja, dan belum ada kurikulum kesehatan reproduksi pada remaja. Hasil survey di Desa Kota Karang diperoleh masih banyak remaja belum mengetahui kesehatan reproduksi, ada kejadian remaja hamil diluar nikah dan menikah di usia muda $(<20$ tahun). Target dan luaran yang dari kegiatan pengabdian masyarakat ini yaitu remaja memperoleh informasi yang tepat mengenai kesehatan reproduksi dan memahami serta dapat melaksanakan dalam kehidupan sehari-hari untuk meningkatkan kesehatan remaja khususnya kesehatan reproduksi. Tahapan yang dilaksanakan dalam kegiatan ini meliputi: 1). melakukan survey ke lokasi (Desa Kota Karang Kec. Kumpeh Ulu), 2). mencari informasi tentang kesehatan remaja di Desa Kota Karang Kec. Kumpeh Ulu, 3). melakukan promosi kesehatan di Desa Kota Karang Kec. Kumpeh Ulu, dan 4). melakukan evaluasi dari promosi yang dilakukan. Remaja memperoleh informasi yang tepat mengenai kesehatan reproduksi dan memahami serta dapat melaksanakan dalam kehidupan sehari-hari untuk meningkatkan kesehatan remaja khususnya kesehatan reproduksi.
\end{abstract}

Kata Kunci: Peningkatan Kesehatan; Remaja; Reproduksi Sehat 


\section{PENDAHULUAN}

Masa remaja merupakan salah satu tahap antara masa kanak-kanak dengan masa dewasa. istilah ini menunjukkan masa dari awal pubertas sampai tercapainya kematangan yang biasa dimulai dari usia 14 tahun pada pria dan usia 12 tahun pada wanita. Transisi ke masa dewasa bervariasi dari satu budaya ke budaya lain, namun secara umum diidentifikasikan sebagai waktu dimana individu mulai bertindak lepas dari orang tua mereka.

Remaja pada umumnya menghadapi permasalahan yang sama untuk memahami tentang seksualitas, yaitu minimnya pengetahuan tentang seksualitas dan kesehatan reproduksi yang disebabkan oleh terbatasnya akses informasi dan advokasi remaja, tidak adaya akses pelayanan yang ramah terhadap remaja, masih terbatasnya institusi di pemerintah yang menangani remaja secara khusus. Selain itu belum adanya Undang-Undang (UU) yang mengakomodir hak-hak remaja, dan belum adanya kurikulum mengenai kesehatan reproduksi pada remaja sekolah juga menjadi permasalahan pada remaja untuk memahami tentang seksualitas. Salah satu masalah yang sering timbul pada remaja terkait dengan masa awal kematangan organ reproduksi adalah perilaku seks bebas (free sex), masalah kehamilan diluar penikahan, dan terjangkitnya penyakit menular seksual termasuk HIV/ AIDS.

Proses dalam tumbuh kembang remaja harus mendapat perhatian khusus supaya dapat terkontrol pada fase tersebut. kontrol dan regulasi perlu dilakukan terhadap doronga-dorongan seks dan impuls-impuls seks, agar tidak terlampau dan meledakledak, sehingga bisa melemahkan jasmani dan rohani. remaja harus bisa menghindari dan bisa mengontrol pergaulan bebas, bukan malah terjerumus pada dunia pergaulan bebas yang kelak akan merusak masa depan, harapan dan tujuan sebagai generasi muda. perilaku seks berisiko sangat berkaitan erat dengan pergaulan bebas.

Menurut WHO, kesehatan reproduksi merupakan suatu keadaan fisik, mental dan soial yang utuh, bukan hanya bebas dari penyakit kecacatan dalam segala aspek yang berhubungan dengan sistem reproduksi, fungsi serta prosesnya. kesehatan reproduksi juga merupakan suatu keadaan dimana manusia dapat menikmati kehidupan seksualnya serta mampu menjalankan fungsi dan proses reproduksinya secara sehat dan aman. informasi mengenai masalah reproduksi, selain penting diketahui oleh para pemberi layanan kesehatan, pembuat keputusan, juga penting untuk para pendidik dan penyelenggara program bagi remaja, agar dapat membantu menurunkan masalah kesehatan reproduksi remaja.

Fenomena yang terjadi di Indonesia, masih timbul pro dan kontra di msyarakat, dan beranggapan bahwa membicarakan seks merupakan hal yang tabu dan pendidikan seks akan mendorong remaja untuk berhubungan seks. Seksualitas menyangkut bebebrap hal meliputi dimensi biologis, yaitu berkaitan dengan organ reproduksi, cara merawat kebersihan dan kesehatan, dimensi psikologis, seksualitas berkaitan dengan identitas peran jenis, perasaan terhadap seksualitas dan bagaimana menjalankan fungsinya sebagai makhluk seksual, dimensi sosial berkaitan dengan relasi antar manusia serta bagaimana lingkungan berpengaruh dalam pembentukan pandangan mengenai seksul dan pilihan perilaku seks.

Berdasarkan kesepakatan International "The Cairo Consensus" tahun 1994 di kairo tentang kesehatan reproduksi yang berhasil ditandatangani oleh 184 negara termasuk Indonesia, diputuskan bahwa perlunya pendidikan seks bagi para remaja, dalam salah satu butirnya ditekankan tentang upaya untuk mengusahakan dan merumuskan perawatan kesehatan seksual dan reproduksi serta menyediakan 
informasi yang komprehensif termasuk bagi para remaja.

Hasil survey di Desa Kota Karang terhadap remaja, diperoleh bahwa masih banyak remaja yang belum mengetahui tentang kesehatan reproduksi. Selain itu, ada kejadian remaja hamil diluar nikah dan menikah di usia muda $(<20$ tahun $)$. Mengingat banyaknya remaja yang belum memahami mengenai kesehatan reproduksi, adanya kejadian hamil sebelum menikah, dan menikah di usia muda ( $<20$ tahun), di Desa Kota Karang Kecamatan Kumpeh Ulu Kabupaten Muara Jambi, maka penulis dan tim tertarik untuk membantu warga terutama remaja-remaja untuk memberikan pemahaman tentang kesehatan reproduksi dengan cara melakukan promosi kesehatan tentang kesehatan reproduksi. Jumlah pemuda di Desa Kota Karang yang ikut aktif dalam kelompok organisasi kepemudaan lebih dari 50 orang. Kebersamaan dan keakraban yang muncul dikalangan pemuda juga membawa dampak negatif.

Kegiatan pengabdian masyarakat ini mempunyai solusi antara lain meliputi: 1). Memberi informasi tentang kesehatan reproduksi melalui pendidikan kesehatan/ promosi kesehatan, 2). Bekerjasama dengan Kelurahan desa Kota Karang untuk mengadakan penyuluhan pada remaja tentang kesehatan reproduksi.

\section{TARGET DAN LUARAN}

Target dan luaran dari kegiatan pengabdian masyarakat ini yaitu remaja memperoleh informasi yang tepat mengenai kesehatan reproduksi dan memahami serta dapat melaksanakan dalam kehidupan sehari-hari untuk meningkatkan kesehatan remaja khususnya kesehatan reproduksi.

\section{METODE PELAKSANAAN}

Pelaksanaan kegiatan pengabdian kepada masyarakat ini di laksanakan pada bulan Februari-Maret 2017 dengan sasaran remaja di desa Kota Karang Kecamatan Kumpeh Ulu Kabupaten Muara Jambi

Tahapan yang dilaksanakan dalam kegiatan ini meliputi:

1. Melakukan survey ke lokasi (Desa Kota Karang Kec. Kumpeh Ulu),

2. Mencari informasi tentang kesehatan remaja di Desa Kota Karang Kec. Kumpeh Ulu,

3. Melakukan promosi kesehatan di Desa Kota Karang Kec. Kumpeh Ulu

4. Melakukan evaluasi dari promosi yang dilakukan.

\section{HASIL DAN PEMBAHASAN}

Kegiatan yang dilakukan dalam pengabdian masyarakat meliputi beberapa tahapan yang dilaksanakan dalam kegiatan ini meliputi: melakukan survey ke lokasi (Desa Kota Karang Kec. Kumpeh Ulu), mencari informasi tentang kesehatan remaja di Desa Kota Karang Kec. Kumpeh Ulu, melakukan promosi kesehatan di Desa Kota Karang Kec. Kumpeh Ulu, dan melakukan evaluasi dari promosi yang dilakukan.

Pengabdian masyarakat ini mempunyai solusi meliputi: memberi informasi tentang kesehatan reproduksi melalui pendidikan kesehatan/ promosi kesehatan, dan bekerjasama dengan Kelurahan desa Kota Karang untuk mengadalan penyuluhan pada remaja tentang kesehatan reproduksi. kegiatan tersebut dapat dilihat pada gambar berikut:

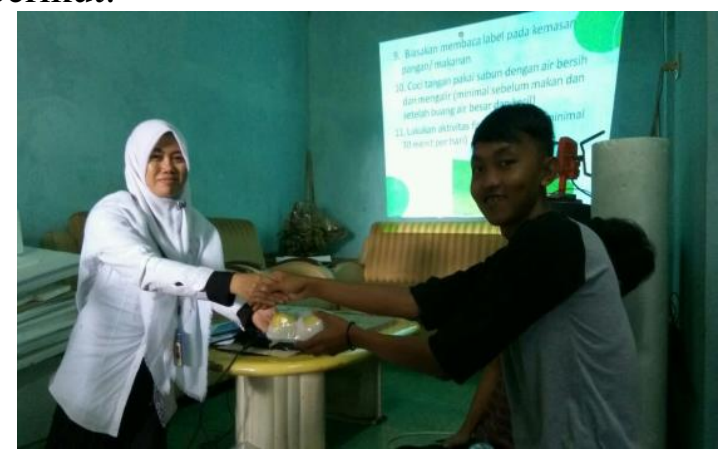

Gambar 1. Memberikan hadiah bagi peserta yang bertanya saat penyuluhan 
Setelah dilakukan promosi kesehatan, remaja memperoleh informasi yang tepat mengenai kesehatan reproduksi dan memahami serta dapat melaksanakan dalam kehidupan sehari-hari untuk meningkatkan kesehatan remaja khususnya kesehatan reproduksi. Kegiatan ini mempunyai manfaat membantu masyarakat khususnya remaja untuk meningkatkan pengetahuannya, dan mampu menangani masalahnya secara tepat. remaja memperoleh informasi yang tepat mengenai kesehatan reproduksi dan memahami serta dapat melaksanakan dalam kehidupan sehari-hari untuk meningkatkan kesehatan remaja khususnya kesehatan reproduksi.

Hal ini ditunjang dari hasil penelitian oleh Widiyanto, Purnomo, dan Sari (2013), bahwa terdapat pengaruh dari pemberian pendidikan kesehatan reproduksi remaja terhadap pengetahuan tentang perilaku seksual. Begitu juga hasil penelitian dari Nasution (2012), bahwa pengetahuan kesehatan reproduksi merupakan variabel yang berpengaruh secara bermakna terhadap perilaku seksual pranikah.

Adapun kelemahan dari kegiatan pengabdian masyarakat ini antara lain kesulitan dalam mengumpulkan remajaremaja dalam kegiatan untuk diberikan penyuluhan.

\section{KESIMPULAN DAN SARAN}

\section{Kesimpulan}

Kegiatan pengabdian kepada masyarakat yang dilakukan pada remaja ini diharapkan remaja memperoleh informasi yang tepat mengenai kesehatan reproduksi dan memahami serta dapat melaksanakan dalam kehidupan sehari-hari untuk meningkatkan kesehatan remaja khususnya kesehatan reproduksi.

\section{Saran}

Diharapkan Puskesmas yang membina wilayah Desa Kota Karang yang menjadi Pusat Kesehatan Masyarakat di daerah tersebut yang terdekat dengan masyarakat dapat memberi informasi tentang kesehatan reproduksi melalui pendidikan kesehatan/ promosi kesehatan secara berkala dan bekerjasama dengan Kelurahan desa Kota Karang untuk mengadakan penyuluhan pada remaja tentang kesehatan reproduksi.

\section{UCAPAN TERIMAKASIH}

Alhamdulillah puji dan syukur penulis panjatkan kehadirat Allah SWT karena berkat rahmat dan hidayahnya laporan pengabdian masyarakat ini dapat diselesaikan. kegiatan pengabdian masyarakat ini ditujukan untuk memberikan pemahaman pada para remaja desa Kota Karang akan pentingnya berperilaku hidup sehat dan mampu menjaga kesehatan reproduksinya.

Terima kasih penulis sampaikan pada STIKes Baiturrahim, Dinas Kesehatan kabupaten Muaro Jambi, Puskesmas Muara Kumpeh dan Tim Pengabdian Masyarakat serta rekan semua yang tidak dapat disebutkan namanya satu persatu atas dukungan dan kesempatan yang diberikan pada penulis dan tim untuk dapat melakukan kegiatan pengabdian masyarakat di Desa Kota Karang kabupaten Muaro Jambi. Penulis dan Tim berharap agar kegiatan ini dapat berkelanjutan agar dapat terpantau dan terbina kelompok pemuda Desa Kota Karang menjadi kelompok pemuda Karang Taruna yang mandiri, berpikiran posistif dan berkehidupan sehat.

\section{DAFTAR PUSTAKA}

Anggariksa, D.E., Ichsan, B., dan Nirlawati, D. 2013. Hubungan pengetahuan tentang kesehatan reproduksi terhadap sikap menghadapi sindrom premenstruasi pada remaja putri siswi $X$ dan XI MAN 2 Madiun (Vol. 5). Jurnal Biomedika.

Estrada, R. 2014. Ilustrasi berwarna anatomi dan fisiologi. Tangerang Selatan: Binarupa Aksara 
Huriah, T., dan Nisma, H. 2008. Pengaruh pendidikan kesehatan reproduksi oleh teman sebaya (Peer Group) terhadap pengetahuan kesehatan reproduksi remaja di SMP Negeri 2 Kasihan Bantul Yogyakarta (Vol 8). Jurnal Mutiara Medika

Kemenkes RI. 2013. Aku bangga aku tahu: petunjuk teknis pembinaan dan penyuluhan kampanye pencegahan HIV-AIDS "aku bangga aku tahu". Jakarta: Kemenkes RI

Miswanto. 2014. Pentingnya Pendidikan Kesehatan Reproduksi dan Seksualitas Pada Remaja (Vol 3, No. 2). Jurnal Studi Pemuda

Nasution, S.L. 2012. Pengaruh Pengetahuan Tentang Kesehatan Reproduksi Remaja terhadap Perilaku Seksual Pranikah Remaja di Indonesia (Vol. 15, No. 1). Widyariset

Susanto, R.C., dan Made, M, G.A. 2013. Penyakit kulit dan kelamin. Yogyakarta: Nuha Medika

Syafrudin, D.A.D., dan Delmaifanis. 2011. Himpunan penyuluhan kesehatan pada remaja, keluarga, lansia dan masyarakat. Jakarta: Trans Info Media (TIM)

Tamher, S., dan Ekasari, M.F. 2009. Pengkajian Keperawatan pada individu, keluarga, dan komunitas. Jakarta: TIM

Widiyanto, B., Purnomo., dan Sari, A.M. 2013. Pengaruh pemberian pendidikan kesehatan reproduksi remaja terhadap pengetahuan tentang perilaku seksual (Vol 1, No.2). Jurnal Keperawatan Komunitas 